18 Revista Latinoamericana de la Papa 20 (1): 18-31

ISSN: 1853-4961

http://www.papaslatinas.org/ojs/index.php/index/oai

\title{
Rizobacterias promotoras de crecimiento de plantas con capacidad para mejorar la productividad en papa
}

\author{
J. $\operatorname{Arcos}^{1}$ y D. Zúñiga ${ }^{2}$
}

Manuscrito recibido: $14 / 08 / 2015$

Aceptado: 15/01/2016

Disponible en línea: Junio 2016

\section{Resumen}

La agricultura moderna industrial de alta producción es una de las principales actividades antrópicas de la emisión de gases de efecto invernadero, particularmente el uso excesivo de agroquímicos (fertilizantes y pesticidas sintéticos); esta alta demanda de agroquímicos puede aliviarse con el uso biológico y genético de especies nativas de plantas y microorganismos. En esta investigación, se evaluaron ocho cepas de Rizobacterias Promotoras del Crecimiento de Plantas (PGPR) nativas por su capacidad para mejorar la productividad de la papa y/o en el control de fitopatógenos, en condiciones de campo de la zona altiplánica de Puno, ubicada a $3820 \mathrm{msnm}$. Resultados mostraron que la altura de plantas y los rendimientos totales de tubérculos en peso y número, en las parcelas inoculadas con las PGPR fueron significativamente superiores en comparación al control no inoculado; en promedio, el rendimiento de la variedad Ccompis incrementó en 125,79\% comparado con el control no inoculado, y el número total de tubérculos se incrementó a 141,41\% por encima del control no inoculado. Las mejores cepas de rizobacterias en que mejoran la productividad de papa fueron: Bac17M8 y Act16M2, con rendimientos superiores en 145,69\% y 140,87\%, respectivamente, en comparación al control no inoculado. Las parcelas inoculadas con PGPR presentaron menor porcentaje de tubérculos infectados con Rhizoctonia solani y Spongospora subterranea comparado con los tubérculos cosechados de la parcela control no inoculada.

Palabras clave adicionales: Rendimiento, tubérculos, fitopatógenos, inoculación, variedad.

Plant growth promoting rhizobacteria with ability to enhance productivity in potato

\section{Summary}

The industrial modern agriculture of high production is one of the main human activities of emission of greenhouse gases, particularly the excessive use of agrochemicals (fertilizers and pesticides synthetic), this high demand for agrochemicals can be alleviated with the increased use of biological and genetic of native species of plants and microorganisms. In this research, eight strains of native Plant Growth Promoting Rhizobacteria (PGPR) with best able to increase the productivity of potato, and/or to control plant pathogens were evaluated, under field conditions. The total yields of tubers by weight and number, in plots inoculated with plant growth promoting rhizobacteria were significantly higher compared to non-inoculated control, average tuber yield of the potato variety Ccompis due to inoculation with rhizobacteria strains increased by $125,79 \%$ compared to non-inoculated control, and the total number tubers increased to $141,41 \%$ over the uninoculated control. Best rhizobacteria strains

Autor para correspondencia. Correo electrónico: jharcos28@ hotmail.com

Estación Experimental Agraria .Illpa-Puno. INIA, Perú. Av. La Molina No 1981. Lima, Perú.

2 Laboratorio de Ecología Microbiana y Biotecnología Marino Tabusso, Dpto. de Biología. Universidad Nacional Agraria la Molina. Av. La Molina. Lima, Perú. 
in promoting productivity of potato were Bac17M8 and Act16M2 with higher yields 145,69 $\%$ and $140,87 \%$, respectively, compared to uninoculated control. The plots inoculated with PGPR had lower percentage of tubers infected with plant pathogens Rhizoctonia solani and Spongospora subterranea compared to tubers harvested from uninoculated control plot.

Additional keywords: Yield, tuber, plant pathogens, inoculation, variety.

\section{Introducción}

La papa (Solanum tuberosum L.) es un cultivo alimenticio de alto valor nutritivo y medicinal, muy valioso para la alimentación de la población mundial en constante crecimiento, y constituye el principal cultivo de los pequeños agricultores de la región andina, donde existe gran diversidad genética de especies de papas cultivadas y silvestres. Sin embargo, a pesar del alto potencial de rendimiento del cultivo de la papa, en el Perú, el promedio de la producción y productividad es bajo, en comparación al rendimiento promedio de otros países. Este rendimiento bajo, entre otros factores, es debido principalmente al ataque de plagas $\mathrm{y}$ enfermedades que afectan el cultivo y por rotaciones intensivas en parcelas cada vez más pequeñas y de baja fertilidad, expuestas a las condiciones adversas del clima (alta radiación solar, heladas y sequías intermitentes). Para mejorar el rendimiento y contrarrestar el daño de plagas y enfermedades, los agricultores hacen uso de fertilizantes y pesticidas químicos, con la consecuente contaminación del medio ambiente, riesgo de toxicidad para la salud humana e incremento de los costos de producción.

La sustentabilidad de la producción de alimentos y la salud ambiental para una población humana en constante crecimiento requiere una reducción significativa del uso de fertilizantes nitrogenados sintetizados químicamente y dar prioridad a la fijación biológica de nitrógeno. Para el mejor aprovechamiento de estos procesos biológicos deberían considerarse el uso óptimo de los sistemas de fijación de nitrógeno conocidos y el desarrollo de nuevas asociaciones de microorganismos y plantas para la fijación de nitrógeno (Olivares et al., 2013).

Actualmente se viene desarrollando innovaciones tecnológicas amigables con el medio ambiente para el manejo de plagas y enfermedades de los cultivos; así como para el manejo de agroecosistemas, con la finalidad de recuperar y mantener la fertilidad de los suelos. Entre estas prácticas, el uso de abonos orgánicos y de microorganismos nativos, como los del grupo de Rizobacterias Promotoras de Crecimiento de Plantas (PGPR) podría ser parte de la solución efectiva en la disminución del uso de agroquímicos y recuperación de la fertilidad de los suelos agrícolas.

Las PGPR son microorganismos del suelo, generalmente bacterias y hongos, que se asocian de manera natural a las raíces de las plantas de una forma mas o menos íntima; facilitan de manera directa $o$ indirecta la disponibilidad de determinados nutrientes para las plantas, tales como nitrógeno, fósforo e hierro (Fulchieri \& Frioni, 1994; García et al., 1995).

Las PGPR pueden tener mecanismos de acción directa o indirecta. Los mecanismos directos ocurren cuando los metabolitos producidos por algunas cepas de rizobacterias son utilizados como reguladores de crecimiento o precursores de éstos por parte de la planta (GutierrezManero et al., 2001; Patten \& Glick, 2002), tienen acción similar a las fitohormonas aplicadas a las semillas y plantas, con una mayor proliferación de pelos radiculares, que incrementan $y$ mejoran la eficiencia de absorción mineral de nitrógeno, fósforo y hierro (Fulchieri \& Frioni, 1994; García et al., 1995); algunas de estas bacterias son: Azotobacter beijerinckii, Azotobacter chroococcum, 
Azospirillum brasilense, Azospirillum lipoferum, Bacillus subtilis, Bacillus megatherium, Bacillus cereus, Pseudomonas putida, entre otras (Reis et al., 2000). Estas bacterias son capaces de producir sustancias fisiológica $\mathrm{y}$ bioquímicamente activas, como vitaminas, giberelinas, citoquininas y ácido indol acético en cantidades significativas, las cuales mediante su acción conjunta estimulan la germinación de las semillas, aceleran el desarrollo de las plantas e incrementan el rendimiento de los cultivos (Lazarovits \& Nowak, 1997), sobre todo en condiciones de estrés ( Torres et al., 2000).

El nitrógeno y el fósforo son dos de los nutrientes esenciales para el crecimiento y desarrollo de las plantas, la agricultura intensiva implica uso de altas cantidades de fertilizantes químicos; por esta razón, las rizobacterias son importantes, no solo en la asimilación de nutrientes sino también en la disminución del uso de fertilizantes y pesticidas (Cakmakci et al., 2005). La inoculación de las PGPR puede estimular la fijación de nitrógeno y la solubilización de fosfatos, haciéndolos más disponibles para las plantas (Martinez \& Dibut, 1996).

Azotobacter chroococcum son bacterias fijadoras de nitrógeno atmosférico, capaces de sustituir entre 30 y $40 \%$ del fertilizante nitrogenado y de incrementar los rendimientos de los cultivos; en cambio Bacillus megatherium var. phosphaticum son bacterias solubilizadoras del fósforo del suelo, capaces de sustituir hasta $70 \%$ del fertilizante fosfórico, poniendo a disposición de las plantas el fósforo almacenado y fijado en el suelo (Chirinos et al., 2006). Si el suelo carece de fosfato disponible, se recomienda la inoculación de la semilla en la siembra con bacterias de Bacillus spp (Omay et al., 1993).

Los mecanismos indirectos ocurren cuando los metabolitos producidos por las PGPR pueden funcionar como antagónicos, involucran aspectos de control biológico, suprimen o inhiben el crecimiento de microorganismos perjudiciales (fitopatógenos) para el desarrollo de las plantas, vía producción de sideróforos, antibióticos, acción de enzimas líticas (glucanasas, quitinasas) o inducción de mecanismos de resistencia (Bashan, 1998; Gutierrez-Manero et al., 2001).

En años recientes, el uso de PGPR para promover el crecimiento de plantas ha incrementado en varias partes del mundo (Mark, 2002). Diversos autores han reportado que la inoculación con PGPR puede resultar en un incremento de germinación, emergencia de plántulas y mejora de crecimiento y rendimiento de varios cultivos cereales y no cereales (Kloepper \& Schroth, 1978; Hassouna, 1990; Kloepper et al., 1986; Javed \& Arshad, 1997; Biswas et al., 2000a, b).

En condiciones de campo, la inoculación con Azotobacter fue efectivo en el mejoramiento del rendimiento de tubérculos $(32.3 \%)$, rendimiento de broza (15.9\%) y número de tubérculos por planta (50\%) comparado al control no inoculado (Zahir \& Arshad, 1996). Similarmente, Javed \& Arshad (1999) condujeron ensayos en macetas y en campo para probar 11 rizobacterias aisladas para la promoción de rendimiento en papa. En ambos ensayos, el rendimiento de tubérculos, número de tubérculos y peso de brotes mas raíces se incrementaron significativamente en respuesta a la inoculación.

Jiménez et al. (2001) reportaron que Bacillus subtilis, además, de tener efectos antagónicos con fitopatógenos también es promotora del crecimiento, debido a que en las parcelas inoculadas con ella, se produjo mayor cantidad y calidad de tubérculos. Por esta razón, esta investigación tuvo el objetivo de evaluar la capacidad de las Rizobacterias Promotoras de Crecimiento de Plantas (PGPR) en la promoción del 
crecimiento y productividad del cultivo de papa, bajo condiciones de campo.

\section{Materiales y métodos}

\section{Localización del ensayo}

El ensayo se realizó en condiciones del campo experimental del INIA-Puno, situado en la localidad de Salcedo, distrito, provincia y departamento de Puno; ubicado a $3820 \mathrm{msnm}, 15^{\circ} 14^{\prime} 35^{\prime}$ ' latitud Sur y $70^{\circ} 43^{\prime} 30^{\prime}$ ' longitud Oeste. En este ensayo se evaluaron ocho cepas de Rizobacterias Promotoras de Crecimiento de Plantas (PGPR), nativas de las zonas productoras de papa de la región andina y con capacidad para promover el rendimiento de la papa y/o en el control de Rhizoctonia solani (Bac20M1, Act16M2, Bac17M10, Bac17M8, Azo16M2, Azo1M4, Azo2M2 y Azo18M1), las cuatro primeras cepas, aisladas de la rizósfera del cultivo de papa de las zonas productoras de Puno y las cuatro últimas cepas de otras zonas productoras de la región andina (Calvo et al., 2010), un tratamiento con estiércol sólo (estiércol de ovino), un tratamiento con estiércol mas fertilización química (60-60$60 \mathrm{~kg} / \mathrm{ha}$ de $\mathrm{N}, \quad \mathrm{P}_{2} \mathrm{O}_{5}$ y $\left.\mathrm{K}_{2} \mathrm{O}\right)$, un tratamiento de Bac20M1 mas fertilización química (60-60-60 kg/ha de $\mathrm{N}, \mathrm{P}_{2} \mathrm{O}_{5} \mathrm{y}$ $\mathrm{K}_{2} \mathrm{O}$ ), y un tratamiento de Act16M2 mas fertilización química $(60-60-60 \mathrm{~kg} / \mathrm{ha}$ de $\mathrm{N}, \mathrm{P}_{2} \mathrm{O}_{5}$ y $\mathrm{K}_{2} \mathrm{O}$ ); en total 12 tratamientos más un testigo absoluto. A los 12 tratamientos se aplicaron estiércol de ovino, en la cantidad de 5 t/ha.

El suelo experimental presentó una clase textural franco, contenido de materia orgánica de valor medio $(2,59 \%), \mathrm{pH}$ cercano a neutro $(6,40)$, contenido alto de fósforo $(27,10 \mathrm{ppm}) \mathrm{y}$ medio de potasio (148.00 ppm). Se utilizó la variedad de papa nativa Ccompis, caracterizada por su alta calidad culinaria $(26 \%$ de materia seca), sembrada extensivamente en las condiciones agroecológicas de la región altiplánica del Perú por su tolerancia a factores abióticos y bióticos adversos, con 130 días de periodo vegetativo, aproximadamente.

\section{Diseño experimental}

La parcela se instaló en un diseño de bloques completos al azar (BCA), con 12 tratamientos, un testigo absoluto y cuatro repeticiones.

\section{Inoculación de rizobacterias y siembra de tubérculos-semillas}

La inoculación de las PGPR se realizó a los tubérculos-semillas; para lo cual, 150 $\mathrm{mL}$ de cada una de las cepas en estudio a la concentración de 1 x $10^{8} \mathrm{ufc} / \mathrm{mL}$ se disolvieron en $10 \mathrm{~L}$ de agua. Los tubérculos-semillas de papa de la variedad Ccompis fueron sumergidos en esta suspensión o biopreparado por un periodo de tiempo de 8 a 10 minutos; agitándose al principio los tubérculos dentro de la suspensión. Los tubérculos inoculados se sembraron en surcos distanciados a un metro y a $0,30 \mathrm{~m}$ entre tubérculos. Después de la siembra, sobre los tubérculos sembrados se asperjó la suspensión sobrante y luego se colocó el estiércol de ovino a la dosis de $150 \mathrm{~g}$ por tubérculo, seguidamente los tubérculos-semillas dentro de los surcos fueron tapados con una capa de suelo de aproximadamente de 8 a $10 \mathrm{~cm}$. Cada tratamiento se sembró en 6 surcos de 4,5 m de largo, haciendo un área de $27 \mathrm{~m}^{2}$, y se cosechó cuatro surcos centrales, con un área de $18 \mathrm{~m}^{2}$.

\section{Reinoculación de rizobacterias}

A los 65 días después de la siembra, cuando las plantas tenían aproximadamente 15 a $20 \mathrm{~cm}$ de altura se hizo la reinoculación de las cepas de rizobacterias. Para cada parcela de 90 plantas, $50 \mathrm{~mL}$ de una cepa a la concentración de 1 x $10^{8} \mathrm{ufc} / \mathrm{mL}$ se disolvió en $2250 \mathrm{~mL}$ de agua, aplicándose $25 \mathrm{~mL}$ de suspensión o biopreparado por planta. Después de la reinoculación justo al 
cuello de la planta se cubrió con una capa de suelo del primer aporque.

\section{Manejo del cultivo en condiciones de campo experimental}

Para la instalación del experimento, el terreno fue preparado con debida anticipación, inmediatamente después de la cosecha del cultivo anterior con el objetivo de incorporar los rastrojos de cosecha del cultivo anterior y exponer a la radiación solar y al frío las esporas y estados juveniles de muchos enfermedades y plagas. La preparación del terreno consistió de una aradura con un arado de discos, luego el desterronado y mullido del suelo con una rastra de discos en forma cruzada. Un día antes de la instalación del ensayo se realizó el surcado del campo experimental. Cuando las plantas emergieron, a los 45 días después de la siembra, se hizo el elevado de surco para evitar el exceso de agua alrededor de las plantas y favorecer el control de malezas. A los 65 días después de la siembra, cuando las plantas tenían aproximadamente 15 a $20 \mathrm{~cm}$ de altura, inmediatamente después de la reinoculación se realizó el deshierbe y el primer aporque, acumulando una capa de suelo alrededor del cuello de las plantas, con el objetivo de eliminar la presencia de malezas, favorecer el mejor crecimiento de plantas y proteger las rizobacterias de la radiación solar. Después de 20 a 25 días del primer aporque se realizó el segundo aporque depositando una capa de suelo sobre el camellón para evitar la emergencia de estolones y favorecer un buen desarrollo de los tubérculos. Para controlar la polilla de papa Phthorimaea operculella se colocaron trampas con feromonas sexuales.

\section{Variables de respuesta}

Las variables de respuesta fueron: altura de planta en floración (aproximadamente a los 90 días después de la siembra) y en el momento de la cosecha (140 días de la siembra) se determinó el rendimiento en peso y número $\left(\mathrm{kg} / 18 \quad \mathrm{~m}^{2}\right.$ y $\mathrm{N}^{\mathrm{o}}$ tubérculos $/ 18 \mathrm{~m}^{2}$, respectivamente), el grado de incidencia de las enfermedades Rhizoctonia solani y Spongospora subterranea (incidencia es el porcentaje de tubérculos con esclerocios y pústulas, respectivamente) y el contenido de materia seca en los tubérculos. Con los datos obtenidos se realizó un análisis de variancia y para aquellas variables que presentaron diferencias significativas entre los promedios de los tratamientos se realizó la prueba de comparación de medias de LSD con un nivel de significancia de 0,05 .

\section{Resultados y discusión}

La altura de plantas en las parcelas inoculadas con las cepas de rizobacterias fueron estadísticamente superiores en comparación al control no inoculado ( $\mathrm{sin}$ aplicación de estiércol de ovino ni cepa de rizobacterias); siendo de mayor tamaño los tratamientos inoculados con las cepas Bac20M1, Act16M2, Bac17M8 y Azo16M2 (Tabla 1). 
Tabla 1. Altura de plantas $(\mathrm{m})$ de las parcelas inoculadas con rizobacterias y las no inoculadas en la variedad Ccompis.

\begin{tabular}{|c|c|c|}
\hline $\mathbf{N}^{\mathbf{o}}$ & Tratamiento & Altura planta (m) \\
\hline 1 & Bac20 M1 + fert. química $(60-60-60)+5$ t/ha est. Ovino & $0,98 \mathbf{a}$ \\
\hline 2 & Act16M2 + 5 t/ha estiércol ovino & $0,97 \mathbf{a}$ \\
\hline 3 & Bac17M8 + 5 t/ha estiércol ovino & $0,97 \mathbf{a}$ \\
\hline 4 & Act $16 \mathrm{M} 2+$ fert. química $(60-60-60)+5$ t/ha est. Ovino & $0,95 \mathbf{a}$ \\
\hline 5 & Azo16M2 + 5 t/ha estiércol ovino & $0,94 \mathbf{a}$ \\
\hline 6 & Estiércol sólo 5 t/ha + fertilización química (60-60-60) & $0,90 \mathbf{a} \mathbf{b}$ \\
\hline 7 & Bac20 M1 + 5 t/ha est. Ovino & $0,90 \mathbf{a} \mathbf{b}$ \\
\hline 8 & Bac $17 \mathrm{M} 10+5$ t/ha estiércol ovino & $0,88 \quad \mathbf{b}$ \\
\hline 9 & Azo2M2 +5 t/ha estiércol ovino & $0,87 \quad \mathbf{b}$ \\
\hline 10 & Estiércol de ovino sólo 5 t/ha & $0,86 \mathbf{b}$ \\
\hline 11 & Azo18M1 + 5 t/ha estiercol ovino & $0,85 \mathbf{b}$ \\
\hline 12 & Azo1M4 + 5 t/ha estiercol ovino & $0,84 \mathbf{b}$ \\
\hline 13 & Control (no inoculado) sin estiércol de ovino & 0,67 \\
\hline
\end{tabular}

Los promedios seguidos por letras iguales no son diferentes significativamente $(\mathrm{p}<0,05)$

Los rendimientos totales de tubérculos en las parcelas inoculadas con los aislamientos de las rizobacterias fueron significativamente superiores en comparación al control no inoculado.

Las mejores cepas de rizobacterias en promover la productividad de papa fueron
Bac20M1, Bac17M8 y Act16M2, con rendimientos superiores en 152.41, $145.69 \%$ y $140.87 \%$, respectivamente, en comparación al control no inoculado (Tabla 2). 
Tabla 2. Rendimiento total de tubérculos (en peso y número) de papa variedad Ccompis $(\mathrm{p}<0,05)$ por efecto de rizobacterias promotoras de crecimiento de plantas.

\begin{tabular}{|c|c|c|c|}
\hline \multirow{2}{*}{$\mathbf{N}^{\mathbf{o}}$} & \multirow{2}{*}{ Tratamiento } & \multicolumn{2}{|c|}{$\begin{array}{l}\text { Rendimiento total (en peso y } \\
\text { número de tubérculos) }\end{array}$} \\
\hline & & $\left(\mathrm{kg} / \mathbf{1 8} \mathrm{m}^{2}\right)$ & $\mathrm{N}^{0}$ tubérculos $/ \mathbf{1 8} \mathrm{m}^{2}$ \\
\hline 1 & Bac20 M1 +Fert. Química $(60-60-60)+5$ t/ha est. Ovino & $27,79 \mathbf{a}$ & $859,25 \mathbf{a}$ \\
\hline 2 & Bac17M8 + 5 t/ha estiércol ovino & $27,05 \mathbf{a}$ & $886,25 \mathbf{a}$ \\
\hline 3 & Act16M2 + 5 t/ha estiércol ovino & $26,52 \mathbf{a}$ & $842,50 \mathbf{a}$ \\
\hline 4 & Estiércol ovino sólo + Fert. Química (60-60-60) & $26,36 \mathbf{a}$ & $774,25 \mathbf{a}$ \\
\hline 5 & Act16M2 +Fert. Química $(60-60-60)+5$ t/ha est. Ovino & $25,86 \mathbf{a}$ & $812,75 \mathbf{a}$ \\
\hline 6 & Estiércolde ovino sólo 5 t/ha & $25,11 \mathbf{a}$ & $846,25 \mathbf{a}$ \\
\hline 7 & Azo1M4 + 5 t/ha estiércol ovino & $24,94 \mathbf{a}$ & $884,50 \mathbf{a}$ \\
\hline 8 & Azo2M2 +5 t/ha estiércol ovino & $24,88 \mathbf{a}$ & $797,75 \mathbf{a}$ \\
\hline 9 & Bac17M10 + 5 t/ha estiércol ovino & $24,62 \mathbf{a}$ & $749,75 \mathbf{a}$ \\
\hline 10 & Azo18M1 + 5 t/ha estiércol ovino & $24,11 \mathbf{a}$ & $794,75 \mathbf{a}$ \\
\hline 11 & Azo16M2 +5 t/ha estiércol ovino & $24,04 \mathbf{a}$ & $788,00 \mathbf{a}$ \\
\hline 12 & Bac20 M1 + 5 t/ha estiércol ovino & $22,74 \mathbf{a}$ & $716,75 \mathbf{a}$ \\
\hline 13 & Control (no inoculado) sin estiércol de ovino & $11,01 \mathbf{b}$ & $334,50 \quad \mathbf{b}$ \\
\hline
\end{tabular}

Los promedios seguidos por letras iguales no son diferentes significativamente $(\mathrm{p}<0,05)$.

De manera similar, los rendimientos de los tubérculos de la clase primera (tubérculos con peso entre 60 y $80 \mathrm{~g}$, destinados para semilla) y de la papa destinada para consumo fueron significativamente superiores en las parcelas inoculadas con cepas de Bac17M8 y Act16M2 en comparación al control no inoculado. Los rendimientos de la clase primera y papa destinada para consumo fueron superiores en $200 \%$ y $183,33 \%$, respectivamente, en relación al control no inoculado (Tabla 3 ). El rendimiento de tubérculos de las clase segunda fue similar a lo reportado para la clase primera. 
Tabla 3. Rendimiento de tubérculos de clase primera y consumo de papa variedad Ccompis $(\mathrm{p}<0.05)$ por efecto de rizobacterias promotoras de crecimiento de plantas.

\begin{tabular}{|c|c|c|c|}
\hline \multirow{2}{*}{$\mathbf{N}^{\mathbf{o}}$} & \multirow{2}{*}{ Tratamiento } & \multicolumn{2}{|c|}{$\begin{array}{c}\text { Rendimiento clase 1ra y } \\
\text { consumo }\end{array}$} \\
\hline & & $(\mathrm{kg} / \mathbf{1 8 m} 2)$ & $(\mathrm{kg} / \mathbf{1 8 m 2})$ \\
\hline 1 & Bac 17M8 + 5 t/ha estiércol ovino & $3,60 \mathbf{a}$ & $8,80 \mathbf{a}$ \\
\hline 2 & Act16M2 + 5 t/ha estiércol ovino & $3,40 \mathbf{a}$ & $10,30 \mathbf{a}$ \\
\hline 3 & Bac20 M1 +Fert. Química (60-60-60) + 5 t/ha est. ovino & $3,30 \mathbf{a}$ & $9,70 \mathbf{a}$ \\
\hline 4 & Estiércol ovino sólo 5 t/ha + Fert. Química (60-60-60) & $3,30 \mathbf{a}$ & $10,60 \mathbf{a}$ \\
\hline 5 & Estiércolde ovino sólo 5 t/ha & $3,10 \mathbf{a} \mathbf{b}$ & $9,30 \mathbf{a}$ \\
\hline 6 & Azo16M2 + 5 t/ha estiércol ovino & $3,00 \mathbf{a} \mathbf{b}$ & $9,80 \mathbf{a}$ \\
\hline 7 & Act16M2 +Fert. Química $(60-60-60)+5$ t/ha est. ovino & $2,90 \mathbf{a} \mathbf{b}$ & $10,20 \mathbf{a}$ \\
\hline 8 & Bac20 M1 + 5 t/ha estiércol ovino & $2,90 \mathbf{a} \mathbf{b}$ & $7,70 \mathbf{a} \mathbf{b}$ \\
\hline 9 & Azo18M1 + 5 t/ha estiércol ovino & $2,60 \mathbf{a} \mathbf{b}$ & $9,40 \mathbf{a}$ \\
\hline 10 & Azo2M $2+5$ t/ha estiércol ovino & $2,60 \mathbf{a} \mathbf{b}$ & $9,40 \mathbf{a}$ \\
\hline 11 & Bac17M10 + 5 t/ha estiércol ovino & $2,50 \mathbf{a} \mathbf{b}$ & $10,10 \mathbf{a}$ \\
\hline 12 & Azo1M4 + 5 t/ha estiércol ovino & $2,10 \mathbf{a} \mathbf{b}$ & $10,20 \mathbf{a}$ \\
\hline 13 & Control (no inoculado) sin estiércol de ovino & $1,20 \quad \mathbf{b}$ & $2,40 \quad \mathbf{b}$ \\
\hline
\end{tabular}

Los promedios seguidos por letras iguales no son diferentes significativamente $(\mathrm{p}<0,05)$

La efectividad de la inoculación de la semilla con Azotobacter para el mejoramiento del rendimiento de la papa bajo condiciones óptimas de fertilización (NPK 250-150-150 ó 200-100-100 kg ha-1) fueron estudiados en condiciones de campo por Zahir \& Arshad (1996), la inoculación con Azotobacter fue efectivo en el mejoramiento del rendimiento de tubérculos $(32,3 \%)$, rendimiento de broza $(15,9 \%)$ y número de tubérculos por planta (50\%) comparado al control no inoculado. Similarmente, Javed \& Arshad (1999) condujeron ensayos en macetas y en campo para probar 11 rizobacterias aisladas para la promoción de rendimiento en papa. En ambos ensayos, el rendimiento de tubérculos, número de tubérculos y peso de brotes mas raíces se incrementaron significativamente en respuesta a la inoculación.

Jiménez et al. (2001) reportaron que Bacillus subtilis; además, de tener efectos antagónicos con fitopatógenos, también es promotora del crecimiento y rendimiento de papa, debido a que en las parcelas inoculadas con ella, se produjo mayor cantidad y calidad de tubérculos. Dashti et al. (1997) han reportado un incremento en la emergencia, vigor y el peso de plántulas, un mayor desarrollo del sistema radicular y un incremento hasta de $30 \%$ en la producción de cultivos de interés comercial, tales como papa, rábano, tomate, trigo y soya. Los procesos fisiológicos, tales como la tasa fotosintética y uso eficiente de agua se vieron incrementados, lo que se reflejó en un incremento en el rendimiento por hectárea.

Las parcelas inoculadas con los aislamientos de rizobacterias presentaron menor porcentaje de tubérculos infectados con el fitopatógeno Rhizoctonia solani (en promedio $3,74 \%$ ) comparado con los tubérculos cosechados de la parcela control no inoculado $(8,10 \%)$, registrándose una disminución de $4,36 \%$ de tubérculos infectados en las parcelas inoculadas con rizobacterias (Figura 1). Las parcelas inoculadas con las cepas Bac17M8, Act16M2, Azo16M2 y Bac20M1 presentaron menores porcentajes de tubérculos infectados con $R$. solani (1.78, 
$2,39,2,47$ y $2,90 \%$, respectivamente) y una severidad de daño o porcentaje de infección menos del 10\%, en comparación con los tubérculos cosechados de la parcela no inoculada que presentaron una severidad mayor a $25 \%$. Las parcelas inoculadas con las rizobacterias Azo2M2,
Azo1M4 y Bac20M1 más fertilización química, a pesar de que presentaron porcentajes de 6,33, 5,37 y 4,80\% de tubérculos infectados, respectivamente, lo importante es que la severidad de daño en los tubérculos fue bajo (en promedio $8,5 \%)$.

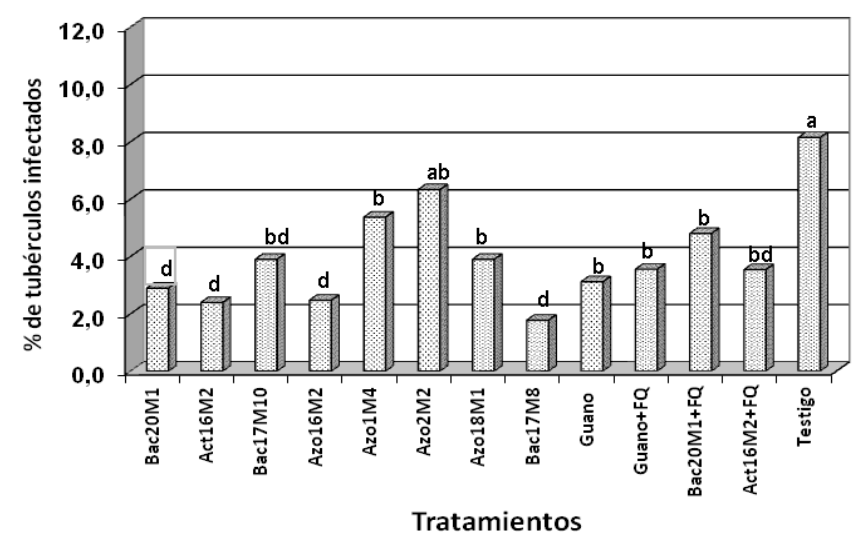

Figura 1. Porcentaje de tubérculos infectados por Rhizoctonia solani.

Estos resultados indican que en condiciones de campo las cepas Bac17M8, Act16M2, Azo16M2 y Bac20M1 tienen efectos antagónicos con Rhizoctonia solani en el cultivo de papa variedad Ccompis. Jiménez et al. (2001) identificaron en cultivo de papa, que la bacteria Bacillus subtilis inhibía prácticamente todos los grupos de anastomosis de Rhizoctonia solani, algunas cepas de Fusarium $s p$ y de Phytophthora infestans. De manera similar, Arcos \& Zúñiga (2015) en condiciones de invernadero reportaron, que las cepas de B. subtilis (Bac17M8 y Bac17M9) y B. amyloliquefaciens nativas de la región altiplánica del Perú y Bolivia, inoculadas a plántulas de dos variedades de papa (Ccompis y Andina), tienen la capacidad de inhibir la infección de $R$. solani.

El mecanismo de acción de biocontrol de patógenos, posiblemente es a través de la producción de diferentes metabolitos por el microorganismo antagonista (PGPR); los cuales, pueden ser sideróforos, antibióticos, bacteriocinas, enzimas y otros compuestos que suprimen o inhiben la acción del patógeno (Leifert et al., 1995). Los estudios de modo de acción revelan que el control biológico por PGPR involucra la producción de metabolitos bacterianos que reducen la población o actividades de fitopatógenos (Kloepper, 1993, 1996; Glick, 1995). Estos metabolitos pueden ser sideróforos que ligado a $\mathrm{Fe}$ los hacen menos disponibles a ciertos miembros de la microflora nativa patogénica (Kloepper et al., 1987). Berthelin et al. (1991) reportaron que la producción de sideróforos ligados al hierro en la rizósfera de la planta los hace no disponible a la microflora dañina en un medio esterilizado.

En relación a la respuesta de las plantas de papa inoculadas con cepas de rizobacterias frente a la incidencia de la roña (Spongosora subterranea); en condiciones de campo, las parcelas inoculadas con los aislamientos de rizobacterias presentaron menor porcentaje de tubérculos infectados con el fitopatógeno Spongospora subterranea (en promedio 2,03\%) 
comparado con los tubérculos cosechados de la parcela control no inoculado $(11,21 \%)$, observándose una disminución de $9.18 \%$ de tubérculos infectados en las parcelas inoculadas con rizobacterias (Figura 2). Las parcelas inoculadas con las cepas Act16M2, Bac17M8, Bac20M1 + FQ y Azo18M1 presentaron menor cantidad de tubérculos con síntomas de $S$. subterranea $(0,56,0,77,0,84$ y $0,98 \%$, respectivamente) y con $8.5 \%$ de severidad de daño, en comparación con los tubérculos cosechados de la parcela no inoculada que presentaron una severidad de daño del 28\%. Mayor cantidad de tubérculos infectados con S. subterranea se observó en los tubérculos cosechados de la parcela control no inoculada $(11,21 \%)$, seguido por los tratamientos: solamente con estiércol sin rizobacteria, inoculada con la cepa Azo16M2 y con Bac20M1 que presentaron incidencias de 6,94, 5,84 y $5,06 \%$, respectivamente; sin embargo, la severidad en los tubérculos fue bajo (en promedio $7,5 \%)$.

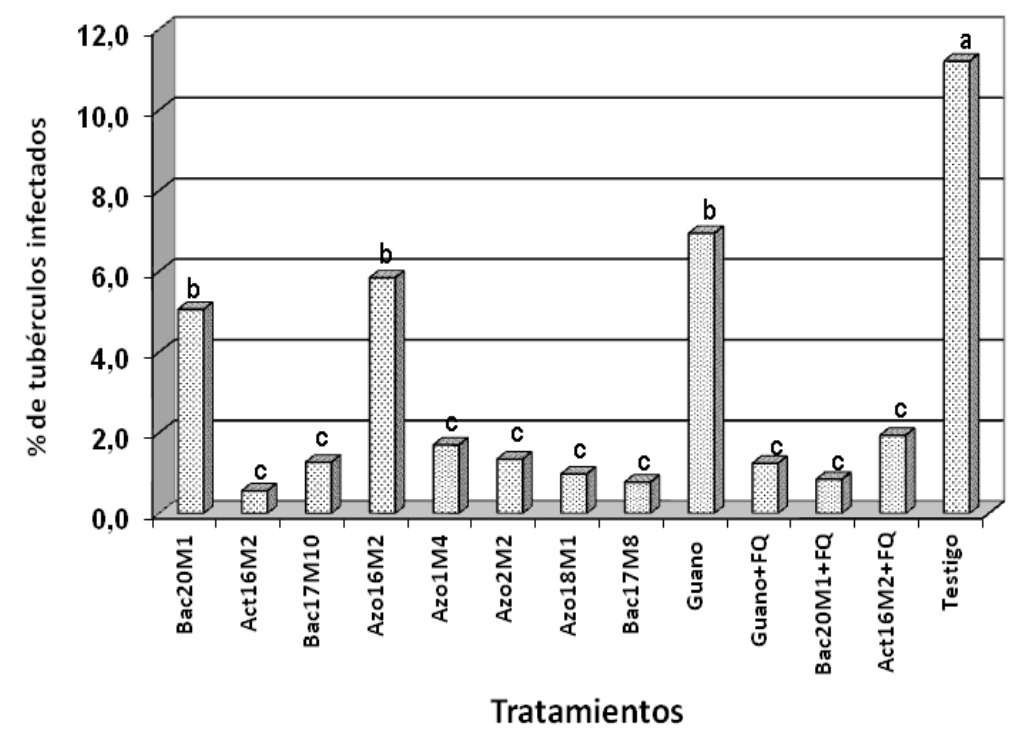

Figura 2. Porcentaje de tubérculos infectados por Spongospora subterránea.

Respecto al contenido de materia seca, los tubérculos cosechados de las parcelas inoculadas con los microorganismos Bac20M1, Azo18M1, Act16M2, Azo1M4, Bac17M8 y Azo16M2 son los que presentaron mayor contenido de materia seca $(158,38,156,73,155,74$. 155,33,
154,05 y $152,09 \mathrm{~g} / 500 \mathrm{~g}$ de papa fresca, respectivamente), en comparación con los otros tratamientos y al control no inoculado (143,50 g/500 $\mathrm{g}$ de papa fresca), obteniéndose en promedio $11,89 \mathrm{~g}$ de materia seca más que el control no inoculado (Tabla 4). 
Tabla 4. Contenido de materia seca $(\mathrm{g} / 500 \mathrm{~g}$ de papa fresca) $(\mathrm{p}<0,05)$ en tubérculos de papa de la variedad Ccompis por efecto de PGPR.

\begin{tabular}{|c|c|c|}
\hline $\mathbf{N}^{\mathbf{o}}$ & Tratamiento & $\begin{array}{c}\text { Materia Seca } \\
(\mathrm{g} / 500 \mathrm{~g})\end{array}$ \\
\hline 1 & Bac20 M1 + 5 t/ha estiércol ovino & $158,38 \mathbf{a}$ \\
\hline 2 & Azo18M1 + 5 t/ha estiércol ovino & $156,73 \mathbf{a}$ \\
\hline 3 & Act16M2 + 5 t/ha estiércol ovino & $155,74 \mathbf{a} \mathbf{b}$ \\
\hline 4 & Azo1M4 + 5 t/ha estiércol ovino & 155,33 a b c \\
\hline 5 & Bac17M8 + 5 t/ha estiércol ovino & 154,05 a b c d \\
\hline 6 & Azo16M2 + 5 t/ha estiércol ovino & 152,09 a b c d e \\
\hline 7 & Act16M2 + fert.química $(60-60-60)+5$ t/ha est. Ovino & 150,93 b c d e \\
\hline 8 & Azo2M2 + 5 t/ha estiércol ovino & 150,53 b c d e \\
\hline 9 & Estiércol sólo 5 t/ha + fertilización química (60-60-60) & 149,8 \\
\hline 10 & Estiércol de ovino sólo 5 t/ha & 148,86 \\
\hline 11 & Bac20 M1 + fert.química $(60-60-60)+5$ t/ha est. Ovino & 148,38 \\
\hline 12 & Bac $17 \mathrm{M} 10+5$ t/ha estiércol ovino & 147,58 \\
\hline 13 & Control (no inoculado) sin estiércol de ovino & 143,50 \\
\hline
\end{tabular}

Los promedios seguidos por letras iguales no son diferentes significativamente $(\mathrm{p}<0,05)$

Las cepas Act16M2, Bac17M8 y Bac20M1 estimularon un mayor contenido de materia seca; estos resultados indican que estas cepas nativas de las zonas productoras de papa de Puno, además de estimular mayor contenido de materia seca también promueven la productividad del cultivo de papa variedad Ccompis y tienen efectos antagónicos con los fitopatógenos Rhizoctonia solani y Spongospora subterranea. Oswald et al. (2010) reportaron que tres bacterias aumentaron los rendimientos de materia seca en comparación con el control fertilizado orgánicamente, alcanzando rendimientos similares a los del control fertilizado inorgánicamente.

Se debe mencionar que el mayor rendimiento registrado con la cepa Bac20M1 se debe posiblemente al efecto de la fertilización química (60-60-60 kg/ha de $\mathrm{N}, \mathrm{P}_{2} \mathrm{O}_{5}$ y $\mathrm{K}_{2} \mathrm{O}$ ); puesto que en el tratamiento, sin la fertilización no tuvo el mismo efecto; además, el análisis económico de la eficiencia de inoculación de las PGPR y aplicación de fertilizantes químicos (Tabla 5) indica que es de menor rentabilidad $(49,41 \%)$ comparado con los índices de rentabilidad de las parcelas inoculadas con las rizobacterias Bac17M8 y Act16M2 $(64,54 \%$ y 56,74\%, respectivamente).

Los tubérculos de la parcela inoculada con la rizobacteria Bac20M1 más fertilización química y de la parcela con solo estiércol más fertilización química presentaron incidencias significativas de Rhizoctonia solani (Figura 1); además, los tubérculos de la parcela aplicada con solo estiércol presentaron mayor porcentaje de tubérculos infectados por Spongospora subterranea (Figura 2). La rentabilidad de la parcela control fue negativa $(-23,54 \%)$ y de la parcela fertilizada químicamente (120-100-80 kg/ha de $\mathrm{N}, \mathrm{P}_{2} \mathrm{O}_{5}$ y $\mathrm{K}_{2} \mathrm{O}$ ) fue de $35,94 \%$ (Tabla 6). 
Tabla 5. Análisis económico de la eficiencia de inoculación de las PGPR y fertilizantes químicos. Salcedo, Puno-Perú.

\begin{tabular}{lrrrrrr}
\hline \multicolumn{1}{c}{ Tratamiento } & $\begin{array}{r}\text { Costo PGPR y } \\
\text { otros insumos }\end{array}$ & $\begin{array}{c}\text { Rendimiento } \\
\mathbf{k g / h a}\end{array}$ & $\begin{array}{c}\text { Ingreso } \\
(\mathbf{S} / / / \mathbf{h a})^{*}\end{array}$ & $\begin{array}{c}\text { Costo total } \\
(\mathbf{S} / .)\end{array}$ & $\begin{array}{c}\text { Ingreso Neto } \\
(\mathbf{S} / .)\end{array}$ & $\begin{array}{c}\text { Rentabilidad } \\
(\%)\end{array}$ \\
\hline Bac 17M8 + estiércol ovino & 540,00 & 14644,00 & 8786,40 & 5340,00 & 3446,40 & 64,54 \\
Act 16M2 + estiércol ovino & 540,00 & 13950,00 & 8370,00 & 5340,00 & 3030,00 & 56,74 \\
$\begin{array}{l}\text { Bac20M1 + estiércol y } \\
\text { fertilización química 60-60-60 }\end{array}$ & 1400,00 & 15439,00 & 9263,40 & 6200,00 & 3063,40 & 49,41 \\
$\begin{array}{l}\text { Estiércol + fertilización } \\
\text { química 60-60-60 }\end{array}$ & 1360,00 & 15028,00 & 9016,80 & 6160,00 & 2856,80 & 46,38 \\
$\begin{array}{l}\text { Control } \\
\text { Fertilizante: 120-100-80 }\end{array}$ & 0,00 & 6117,00 & 3670,20 & 4800,00 & $-1129,80$ & $-23,54$ \\
\hline
\end{tabular}

*S/. 060 por kg de papa

\section{Conclusiones}

En condiciones de campo, algunas cepas de Bacillus, Actinomicetos y Azotobacter pueden mejoran la productividad de la papa variedad Ccompis; mediante algunos mecanismos de promoción del crecimiento y productividad identificadas en las PGPRs, tales como: fijación biológica del nitrógeno atmosférico, solubilización de fosfatos y la síntesis de fitohormonas como el ácido indol acético.

La inoculación de tubérculos-semillas de papa con algunas cepas de PGPRs, no solamente pueden tener capacidad para promover la productividad del cultivo y mayor contenido de materia seca en tubérculos, sino también para suprimir el daño o infección en tubérculos causados por los fitopatógenos Rhizoctonia solani y Spongospora subterranea.

\section{Conflictos de interés}

Los autores declaran que la publicación de este artículo no tiene conflictos de interés.

\section{Agradecimientos}

Al Centro Internacional de la Papa (CIP), al Laboratorio de Ecología Microbiana y Biotecnología "Marino Tabusso" de la Universidad Nacional Agraria La Molina e Instituto Nacional de Innovación Agraria (INIA) por el apoyo financiero.

\section{Referencia citadas}

Arcos, J. \& Zúñiga D. 2015. Efecto de rizobacterias en el control de Rhizoctonia solani en el cultivo de papa. Ecol. Apl. 14(2): 95-101.

Bashan, Y. 1998. Inoculants of plant growth promoting bacteria for use in agriculture. Biotech. Advances 16: 729770 .

Berthelin, J.; Leyrol, C.; Laheurte, F. \& Degiudici, P. 1991. Some considerations on the relations between phosphate solubilizing rhizobacteria and their effect on seedling and plant growth related to phosphorus solubilization. Pp: 359-364. In C. Keel, B. Koller and G. Defago, Eds. Growth Promoting Rhizobacteria: Progress and Prospects. IOBC, Switzerland.

Biswas, J. C.; Ladha, J. K. \& Dazzo, F. B. 2000a. Rhizobia inoculation improves nutrient uptake and growth of lowland rice. Soil. Sci. Soc. Am. J. 64: 1644-1650.

Biswas, J. C.; Ladha, J. K.; Dazzo, F. B.; Yanni, Y. G. \& Rolfe, B. G. 2000b. Rhizobial inoculation influences seedling vigor and yield of rice. Agron. J. 92: 880886.

Cakmakci, R.; Dönmez, F.; Aydin, A. \& Sahin, F. 2005. Growth promotion of 
plants by plant growth promoting rhizobacteria under greenhouse and two different field soil conditions. Soil Biol. And Bioch. J. 38: 1482-1487.

Calvo, P.; Ormeño-Orrillo, E.; MartinezRomero, E. \& Zúñiga, D. 2010. Characterization of Bacillus isolates of potato rhizosphere from Andean soils of Peru and their potential PGPR characteristics. Brazilian Journal of Microbiology 41: 899-906.

Chirinos, J.; Leal, A. \& Montilla, J. 2006. Uso de Insumos Biológicos como Alternativa para la Agricultura Sostenible en la Zona Sur del Estado de Anzoátegui. Revista Digital CENIAP HOY No 11. INIA. El tigre, estado Anzoátegui, Mexico. $7 \mathrm{p}$.

Dashti, N.; Zhang, F.; Hynes, R. \& Smith, D.L. 1997. Plant and Soil 188: 33.

Fulchieri, M. \& Frioni, L. 1994. Azospirillum inoculation on maize effect of yield in field experiment in central Argentina. Soil Biol. Biochem. 26: 921923.

García, G.; Moreno, P.; Peña-Cabriales, J. \& Sanchez-Yañez, J. M. 1995. Respuesta del maíz (Zea mays, L.) a la inoculación con bacterias fijadoras de $\mathrm{N}_{2}$.TERRA 13: 71-79.

Glick, B. R. 1995. The enhancement of plant growth by free living bacterial. Can. J. Microbiol. 41: 109-117.

Gutierrez-Manero, F.; Ramos-Solano, B.; Probanza, A.; Mehouachi, J.; Tadeo, F. \& Talon, M. 2001. The plant growth promoting rhizobacteria Bacillus pumilus and Bacillus licheniformis produce high amounts of physiologically active gibberellins. Physiol. Plant. 111: 206-211.

Hassouna, M. G. 1990. Application of rhizobacteria on barley cultivated on the north-western coast of Egypt. Pp: 20. In Abstract of the Second International Workshop on Plant Growth Promoting Rhizobacteria. Interlaken, Switzerland.
Javed, M. \& Arshad, M. 1999. Potential of plant growth promoting rhizobacteria for enhancing the growth and yield of potato (Solanum tuberosum L.). Sarhad J. Agri. 15: 447-452.

Javed, M. \& Arshad, M. 1997. Growth promotion of two wheat cultivars by plant growth promoting rhizobacteria. Pak. J. Bot. 29: 243-248.

Jiménez, Rocío; Virgen, G.; Tabares, S. \& Olalde, V. 2001. Bacterias promotoras del crecimiento de plantas: agro-biotecnología. Avance y Perspectiva Vol. 20: 395-400.

Kloepper, J. W. 1996. Biological control agents vary in specificity for host, pathogen control, ecological habitat and environmental conditions. Bio. Sci. 46: 406-409.

Kloepper, J. W. 1993. Plant growth promoting rhizobacteria as biological control agents. Pp: 255-274. In F. B. Metting Jr., Ed. Soil Microbial Ecology. Dekker, New York, USA.

Kloepper, J. W.; Hume, D. J.; Scher, F. M.; Singleton, C.; Tipping, B.; Lalibert, E. M.; Fraulay, K.; Kutchaw, T.; Simonson, C.; Lifshitz, R.; Zaleska, I. \& Lee, L. 1987. Plant growth-promoting rhizobacteria on canola (rapeseed). Phytopathology 71: 4246.

Kloepper, J. W.; Scher, F. M.; Laliberte, M. \& Tipping, B. 1986. Emergence promoting rhizobacteria: Description and implication for agriculture. Pp: 155-164. In T. R. Swinburne, Ed. Iron, Siderophores and plant diseases. New York, USA.

Kloepper, J. W. \& Schroth, M. N. 1978. Plant growth-promoting rhizobacteria on radishes. In: Proceedings of the Fourth International Conference on plant pathogenic bacteria, INRA. Angers (Francia) 2: 879-882.

Lazarovits, G. \& Nowak, J. 1997. Rhizobacteria for improvemente of plant growth and establishment. Scientia Horticulturae 32: 188-192. 
Leifert, C.; Li, H.; Chidburee, S.; Hampson, S.; Workman, S.; Sigee, D.; Epton, H. \& Harbour, A. 1995. Antibiotic production and biocontrol activity by Bacillus subtilis CL27 and Bacillus pumilus CL45. J. Appl. Bacteriol. 78: 97108.

Mark, G. L. 2002. Tendencias actuales en Agricultura Sostenible, "El uso de inoculantes a base de microorganismos y sus beneficios para la agricultura sostenible". Boletín técnico $\mathrm{N}^{\circ} 1$ de ECOSAFE. Cork, Irlanda. 4 p.

Martinez, R. \& Dibut, B. 1996. Los biofertilizantes como pilares básicos de la agricultura sostenible. Pp: 63-81. En INIFAT. Curso Taller "Gestión Medio Ambiental del desarrollo rural". Cuba.

Omay, S.; Schmidt, W. A. \& Martin, P. 1993. Indolacetic acid production by the rhizosphere bacterium Azospirrillum brasilense $\mathrm{Cd}$. Under in vitro conditions. Can. J. Microbiol. 39: 187-192.

Olivares, J.; Bedmar, E. J. \& San Juan, J. 2013. Biological Nitrogen Fixation in the context of Global Change. American Phytopathological Society. 26: 486-494.
Oswald, A.; Calvo, P.; Zúñiga, D. \& Arcos, J. 2010. Evaluating soil rhizobacteria for their ability to enhance plant growth and tuber yield in potato. Ann. Appl. Biol. 157: 259-271.

Patten, C. L. \& Glick, B. R. 2002. Role of Pseudomonas putida indolacetic and indevelopment of the host plant root system. Appl. Environ. Microbiol. 98: 3795-3801.

Reis, V. M.; Baldani, J. I.; Valdani, V.L.D. \& Dobereiner, J. 2000. Biological dinitrogen fixation in grammineae and palm trees. Crit. Rev. Plant. Soil 19: 227247.

Torres, G.; Valencia, A.; Bernal, P.; Castillo, M. \& Nieto, P. 2000. Isolation of Enterobacteria, Azotobacter $s p$ and Pseudomonas $s p$ producers of Indol 3 Acetic Acid and Siderophores from Colombian rice rhizosphere. Revista Latinoamericana de Microbiología: 171175.

Zahir, Z. A. \& Arshad, M. 1996. Effectiveness of Azotobacter inoculation for improving potato yield under fertilized conditions. Pak. J. SoilSci. 33: 1-8. 